First, even allowing for the reduction in the number of consultant posts in infectious diseases suggested in the Platt report ${ }^{1}$ the number which will be theoretically available in the near future is far in excess of two. However, in case any senior registrars in other specialties should be dazzled by promotion prospects in this field let me explain to them what happens when a consultant in infectious diseases retires. Frequently he is not replaced; if he is replaced it may be by a candidate without special knowledge or training in infectious diseases. On occasions the original consultant's deputy is privileged to run the unit in the capacity of S.H.M.O perhaps "responsible" to some other person without special training in the field. How has this sad situation developed?

There are three main reasons :

Until recently those who have achieved consultant status in infectious diseases have not been sufficiently aggressive in bringing these facts to the notice of those who are in a position to decide such matters. There is evidence that this is changing.

A number of clinicians, mostly general physicians, have been said to resent consultant appointments in infectious diseases. This may have arisen because some consultants in this field were appointed without becoming members of a Royal College, and the Royal College of Physicians has not reorganized the specialty in its training requirements. Resentment may have been increased by the fact that infectious diseases units continue to admit a good proportion of highly interesting clinical material.

There is virtually a total lack of appreciation in this country that infections may require special skills for their proper diagnosis and management. Even in units where sophistication in most fields is expected the approach to infection is of ten Stone Age. One of the difficulties is that infection is extremely common-every doctor who prescribes antibiotics must realize the truth of this.

One regards with envy our Scottish and American colleagues, who realize that the twin sisters of microbiology and infectious diseases cannot be separated, and when they are appointed as specialists in these fields assume their deserved status. When students or house-officers approach me with a view to specializing in infectious diseases I have to warn them that there is no future for them here. We are expected to teach students but not to fire their imagination.

Surely it is time for the Royal Colleges and the Ministry either to admit that their policy is the present laissez-faire situation in which all, including patients, suffer, or provide a proper career structure as in any other specialty ?-I am, etc.,

Royal Free Hospital,

Infectious Diseases Unit,

Coppetts Wood Hospital,
London N.10.

REFERENCE

1 Medical Staffing Structure in the Hospital Service R.M.S.O., London.

\section{Drug Literature}

SIR,-I should like to make a plea through the B.M.F. to some of the manufacturers of pharmaceutical preparations to improve the literature that they send out, both with their preparations and as separate items. I am particularly concerned about the information distributed about the side-effects and toxic effects of drugs, and would like them to give more details about these items, together with references to published work. In addition, anything known about the L.D.50 in animals of their particular preparations should also be published in their literature, because this can be very useful.

The information in the literature distributed these days by the majority of manufacturing chemists is both comprehensive and helpful. However, there are cases in which the information is inadequate, and one has to telephone or write to firms for information which quite often was already available in their files and which they could have very easily published in their literature.-I am, etc.,

Nolan A. WynNe, \section{Royal Victoria Infirmary,
Newcastle upon Tyne.} Director, Poisons Information Centre.

\section{Glycosuria of Pregnancy}

SIR,-I would appreciate the opportunity of replying to further criticisms of my article on the above subject (28 January, p. 205).

Dr. Rosemary M. Robertson (11 March, p. 635) has made the interesting suggestion that pregnant women who are Clinistix-negative on random sampling may have the same incidence of diabetes as the group who are Clinistix-positive. This has a certain plausibility, since the negative group is potentially positive, and is only negative by the chances of random sampling. Dr. Robertson goes on to point out that if her assumption was correct the incidence of diabetes in pregnancy as a whole would be the same as that in the positive group-that is, $1.9 \%$, which is approximately the incidence in the genera population. There are reasons, however, why the Clinistix-positive group cannot be regarded as identical with the negative group as regards incidence of diabetes.

It is a matter of common experience that glucose-tolerance tests in diabetes will yield a higher percentage of Clinistix-positive urine specimens than in renal glycosuria, in which condition as a rule only one or two samples out of the six are positive. It would follow that random sampling of diabetics will yield a higher percentage of positives than a similar sampling of non-diabetics. Consequently, diabetics are more likely to find themselves in the Clinistix-positive than in the Clinistix-negative group. The two groups, in short, are not identical in diabetic incidence.

Attempts to use the diabetes-rich positive group for screening would still lead to missed diabetics, since an unknown percentage of them would-by the chances of random sampling-be lost to the negative group.

Incidence of diabetes was not, however, the theme of my paper, and the data obtained were a mere by-product of the glycosuria studies. The number of diabetics found in the population of 2,547 cases of pregnancy was 7 (4 known, 3 discovered) or $0.28 \%$ if allowance is made for the fact that only half the glycosurias in the second series of 1,000 had glucose-tolerance tests performed the estimated number would be 8 , or $0.33 \%$. As against this, the control population of 537, whose giycosurias were all followed up by glucose-tolerance tests, yielded 9 diabetics (4 known, 5 discovered) $-1.6 \%$ or 5 times the incidence in pregnancy.
The pregnancy populations studied were quite unselected, being patients attending the laboratory for $\mathrm{Rh}$ antibodies and other blood tests ; diabetics were not excluded.

Dr. J. E. Tovey (11 March, p. 635) has ingeniously accounted for the whole phenomenon of pregnancy glycosuria in terms of increased glomerular filtration rate, but he must be well aware that there are other explanations, such as the increased level of corticosteroids well known to occur in pregnancy. The effect of prednisone, for example, in promoting the excretion of glucose can be readily demonstrated, and in a self-experiment $20 \mathrm{mg}$. taken orally increased a 24 -hour excretion of $68 \mathrm{mg}$. to $900 \mathrm{mg}$., and induced a state of strong Clinistix-positiveness in the urine for over six hours without producing any abnormality in the blood-sugar curve.I am, etc.,

Pathological Laboratory,

Kitwe Cen

J. FINE.

\section{Vocational Training}

SIR,-Your issue (18 March, p. 693) reported on a conference on the "Future of British Medicine" held in Newcastle upon Tyne on 10 and 11 March. Several of the speakers were reported as stressing the need for special vocational training of general practitioners. This need has been recognized for some time by such bodies as the B.M.A., the Royal Colleges, the Health Departments and the like, but there is only limited evidence that any practical steps have been taken to provide such vocational training.

Your readers may be interested therefore to know that a vocational training scheme for general practice has recently been introduced in the Lothians in association with the Joint Advisory Committee on health services for Livingston New Town. The Joint Committee represents all aspects of the health service, and has the duty of advising as to how best to provide an integrated service in Livingston, and sees training for general practice as one of the steps towards this goal.

The vocational training scheme which was advertised recently in the B.M.F. is a threeyear course starting at senior house officer or registrar level. This course is supervised throughout by the medical adviser to the Livingston Joint Committee. There is a year's hospital training, a year's general practice training with a prescribed syllabus of work, three months' training in public health, and an elective period in which the trainee has a wide choice in his last nine months. A close association with the district hospital is maintained throughout the course, at the end of which the trainee will be offered a post in general practice in Livingston practising from a health centre, and also his association with the hospital will be maintained, if possible by offering him a parttime appointment.

The Secretary of the Joint Advisory Committee is the Clerk to the Lothians and Peebles Executive Council, 25 Stafford Street, Edinburgh 2, who will be willing to supply any further particulars.-I am, etc.,

JoHN BALDWIN, Medical Adviser,
Livingston New Town Advisory
Committee.

Midlothian 